\title{
Risk factors for methamphetamine use in youth: a systematic
} review

\author{
Kelly Russell ${ }^{1}$, Donna M Dryden ${ }^{1}$, Yuanyuan Liang1, Carol Friesen ${ }^{1}$, \\ Kathleen O'Gorman ${ }^{1}$, Tamara Durec ${ }^{1}$, T Cameron Wild ${ }^{2}$ and \\ Terry P Klassen*1,3
}

\author{
Address: ${ }^{1}$ Department of Pediatrics, University of Alberta, Edmonton, Canada, ${ }^{2}$ School of Public Health, University of Alberta, Edmonton, Canada \\ and ${ }^{3}$ Department of Pediatrics, University of Alberta, Aberhart Centre, Room 8213, 11408 University Avenue, Edmonton, Alberta, T6G 2J3, \\ CANADA \\ Email: Kelly Russell - krussell@ualberta.ca; Donna M Dryden - ddryden@ualberta.ca; Yuanyuan Liang - yliang@ualberta.ca; \\ Carol Friesen - carol_friesen@hotmail.com; Kathleen O'Gorman - kogorman@ualberta.ca; Tamara Durec - tamara.durec@gmail.com; T \\ Cameron Wild - cam.wild@ualberta.ca; Terry P Klassen* - terry.klassen@ualberta.ca \\ * Corresponding author
}

Published: 28 October 2008

BMC Pediatrics 2008, 8:48 doi:10.1/86/|47|-243|-8-48

This article is available from: http://www.biomedcentral.com/I47I-243I/8/48

(c) 2008 Russell et al; licensee BioMed Central Ltd.

This is an Open Access article distributed under the terms of the Creative Commons Attribution License (http://creativecommons.org/licenses/by/2.0), which permits unrestricted use, distribution, and reproduction in any medium, provided the original work is properly cited.

\begin{abstract}
Background: Methamphetamine (MA) is a potent stimulant that is readily available. Its effects are similar to cocaine, but the drug has a profile associated with increased acute and chronic toxicities. The objective of this systematic review was to identify and synthesize literature on risk factors that are associated with MA use among youth.

More than 40 electronic databases, websites, and key journals/meeting abstracts were searched. We included studies that compared children and adolescents ( $\leq 18$ years) who used MA to those who did not. One reviewer extracted the data and a second checked for completeness and accuracy. For discrete risk factors, odds ratios (OR) were calculated and when appropriate, a pooled OR with $95 \%$ confidence intervals $(95 \% \mathrm{Cl})$ was calculated. For continuous risk factors, mean difference and $95 \% \mathrm{Cl}$ were calculated and when appropriate, a weighted mean difference (WMD) and $95 \% \mathrm{Cl}$ was calculated. Results were presented separately by comparison group: low-risk (no previous drug abuse) and high-risk children (reported previous drug abuse or were recruited from a juvenile detention center).

Results: Twelve studies were included. Among low-risk youth, factors associated with MA use were: history of heroin/ opiate use $(\mathrm{OR}=29.3 ; 95 \% \mathrm{Cl}$ : 9.8-87.8), family history of drug use $(\mathrm{OR}=4.7 ; 95 \% \mathrm{Cl}$ : 2.8-7.9), risky sexual behavior $(\mathrm{OR}=2.79 ; 95 \% \mathrm{Cl}: 2.25,3.46)$ and some psychiatric disorders. History of alcohol use and smoking were also significantly associated with MA use. Among high-risk youth, factors associated with MA use were: family history of crime $(\mathrm{OR}=2.0$; $95 \% \mathrm{Cl}: \mathrm{I} .2-3.3)$, family history of drug use $(\mathrm{OR}=4.7 ; 95 \% \mathrm{Cl}: 2.8-7.9)$, family history of alcohol abuse $(\mathrm{OR}=3.2 ; 95 \%$ $\mathrm{Cl}$ : I.8-5.6), and psychiatric treatment $(\mathrm{OR}=6.8 ; 95 \% \mathrm{Cl}$ : 3.6-12.9). Female sex was also significantly associated with MA use.

Conclusion: Among low-risk youth, a history of engaging in a variety of risky behaviors was significantly associated with MA use. A history of a psychiatric disorder was a risk factor for MA for both low- and high-risk youth. Family environment was also associated with MA use. Many of the included studies were cross-sectional making it difficult to assess causation. Future research should utilize prospective study designs so that temporal relationships between risk factors and MA use can be established.
\end{abstract}




\section{Background}

Methamphetamine (MA), also known as crystal meth, is a synthetic stimulant that affects the brain and central nervous system[1-4]. Smoking is the most common route of administration for MA[5]. When smoked or injected, it produces an initial rush that lasts only a couple of minutes but is intensely pleasurable[5]. This is followed by a prolonged high that results in an extended period of euphoria[5]. The half-life of MA ranges from 10-30 hours depending on the purity of the drug, urine $\mathrm{pH}$, and the amount consumed[2]. Like other psychoactive drugs of abuse, chronic MA use can result in tolerance, where increased amounts of MA are required to produce the same high[6].

Because MA is a stimulant, it produces physiological and psychological effects similar to those elicited by cocaine[1]. MA stimulates the release of dopamine, norepinephrine, and serotonin, and blocks their reuptake[7]. This excess amount of neurotransmitters in the synapses produces sensations of euphoria, lowered inhibitions, feelings of invincibility, increased wakefulness, heightened sexual experiences, and hyperactivity resulting from increased energy for extended periods of time[8]. Deleterious short-term effects include increased heart and respiration rates, hyperthermia, chest pain, hypertension, increased respiration, decreased appetite, anorexia, irritability, confusion, tremors, convulsions, anxiety, aggressiveness, and symptoms of psychosis such as hallucinations and paranoia $[4,9,10]$. This is followed by mental and physical exhaustion, headaches, irritability, reduced concentration, hunger, decreased energy, anhedonia, and a craving for more $M A[3,11]$. Cognitive impairments and changes in the brain that result in symptoms similar to those of Parkinson's disease can occur[12,13]. Long-term use of MA use is associated with neurotoxicity, neurodegeneration, and clinical depression that may lead to homicidal and suicidal ideation and action[5].

MA is produced, or "cooked" quickly, reasonably simply, and cheaply by using legal and readily available ingredients, including ephedrine, pseudoephedrine, red phosphorous, iodine, ammonia, paint thinner, lye, camping fuel, drain cleaner, and lithium[5]. These components and cooking tools can be purchased at local drug stores and hardware stores, and recipes can be found on the Internet[14]. Many of the chemicals used in the production of MA are explosive and the generated waste products are corrosive and toxic[15].

In 2004, the US National Survey on Drug Use and Health surveyed persons over the age of 11 and found that 1.4 million people ( $0.6 \%$ of the population) had used MA in the past 12 months, and $600,000(0.2 \%)$ had used it in the previous month[16]. School-based drug surveys administered in Ontario and Manitoba specifically asked about MA use $[17,18]$. They found that between $2.7 \%$ and $3.3 \%$ of students reported using MA within the last year. In another Canadian province, $4 \%(108,000)$ of Albertans aged 15 or older reported using more than one amphetamine-type stimulant[4]. In 2002, street youth aged 14-30 years were surveyed and $71 \%$ of respondents reported using amphetamine-type stimulants and 57\% had used them on more than ten occasions[4].

Because MA is easily accessible, relatively cheap, and has reinforcing properties, chronic use can pose a significant danger[4]. If risk factors for MA use could be identified, physicians and other health care professionals who work with youth may be better equipped to identify MA users and develop education and prevention programs that could be targeted to youth at greater risk for using MA. Thus, we performed a systematic review to identify factors at the individual, family, and community level that are associated with MA use among children and adolescents.

\section{Methods \\ Literature search}

We searched over 40 electronic databases, including MEDLINE $^{\circledast}$, Ovid MEDLINE ${ }^{\circledast}$ In-Process \& Other NonIndexed Citations, EBM Reviews - Cochrane Central Register of Controlled Trials, EMBASE, CINAHL ${ }^{\oplus}$, PsycINFO ${ }^{\oplus}$, International Pharmaceutical Abstracts, Pascal, Global Health, Science Citation Index Expanded and Social Sciences Citation Index (via Web of Science ${ }^{\circledR}$ ), Social Sciences Abstracts, and Psychology and Behavioral Sciences Collection. Trials registers (Current Controlled Trials, ClinicalTrials.gov, the Australian Clinical Trials Registry, and the National Research Register in the United Kingdom) were searched for additional trials. Search terms such as methamphetamine, variant spellings of methamphetamine, amphetamine-related disorders, and crystal meth, were adapted for each database and appropriate subject headings and keywords were used. In addition, an extensive search for grey literature was conducted. Hand searching was conducted in relevant scientific journals, scientific meetings, and the reference lists of relevant reviews and included studies were reviewed. We restricted the search results to English-language studies. The literature search is considered up to date as of May 15, 2006. Full search strategies and lists of resources searched are available [see Additional file 1].

\section{Study selection and inclusion criteria}

Two reviewers independently screened the titles and, when available, the abstracts. Based on general inclusion criteria, studies were classified as "potentially relevant", "irrelevant", and "unclear". The full text of studies described as "potentially relevant" and "unclear" was 
obtained and two reviewers independently applied the specific inclusion criteria. Studies were included if they compared children $\leq 18$ years of age who did and did not use MA (the comparison group could be other drug users or children who do not use drugs). The following study designs were included: case-control, cohort, and cross-sectional. Studies were excluded if they did not have a comparison group, if the outcomes were not measured quantitatively or if they were uncontrolled before and after studies, case-series, or case studies. Disagreements were resolved through discussion or through third party adjudication, as necessary.

\section{Methodological quality assessment}

Two reviewers independently assessed methodological quality; discrepancies were resolved through consensus or by third party adjudication as required. Observational studies were assessed using the Downs and Black checklist[19]. This tool comprises six sections that assess reporting, external validity, internal validity (bias), internal validity (confounding), and power.

\section{Data extraction}

Data were extracted by one reviewer and checked for accuracy and completeness by a second reviewer. A standard data extraction form was developed and the data were subsequently entered into an electronic database. For each included study, we extracted information about the population (demographics and sources), type of study (study design, prospective or retrospective data collection), definitions and details of risk factors, and the numeric results.

\section{Data analysis}

After reviewing the studies that met our inclusion criteria, we made a post hoc decision to group the studies and conduct the data analysis by the nature of the comparison group: 1) youth who did not use illicit drugs (referred to as "low-risk") and 2) youth who abused illicit drugs other than MA or were recruited from juvenile detention centers (referred to as "high-risk"). For dichotomous risk factors (e.g., sex) we calculated pooled odds ratios (OR) with 95\% confidence intervals (95\% CI), where appropriate. For continuous risk factors (e.g., years of education) we calculated weighted mean difference (WMD) and 95\% CI using the DerSimonian and Laird random effects model[20]. A random effects model was used because it allows for combining heterogeneous results where the heterogeneity cannot readily be explained[21]. The resulting estimate is more conservative because the resulting confidence intervals are wider. Statistical heterogeneity was assessed using the $\mathrm{I}^{2}$ statistic, which describes the percentage of total variation across studies that is due to heterogeneity rather than chance. For this review a value greater than $50 \%$ was considered as substantial heterogeneity[22]. In instances where only one study reported the specific risk factor or where pooling was not appropriate, the effect estimate (OR or WMD) and 95\% CI were reported for each risk factor.

\section{Results}

\section{Literature search}

The database, grey literature searches and hand searching yielded 2,376 potentially relevant studies. In total, 106 unique studies were reviewed and 13 met our inclusion criteria. Of these, two studies assessed risk factors in the same population and are treated as one study for the purposes of this report[23]. Therefore, our review includes 13 publications but only 12 unique studies. Study retrieval and selection is outlined in Figure 1.

Studies were excluded from the review for the following reasons: not relevant to the topic $(\mathrm{n}=34)$, incorrect study population $(\mathrm{n}=33)$, inappropriate study design $(\mathrm{n}=12)$, not primary research $(\mathrm{n}=13)$, and inadequate data $(\mathrm{n}=$ $1)$.

\section{Description of included studies}

The characteristics of the 12 included studies and populations are presented in Tables 1 [see Additional file 2] and 2 [see Additional file 3]. Most studies relied on selfreported MA use. Three studies administered urine tests to determine MA use[24-26] and one study diagnosed children with MA dependence[27]. The remaining studies relied on self-reported MA use. Seven studies were conducted in North America [27-33] and the remaining five in Asia[23,24,26,34,35]. The majority of the studies were published recently; the median year of publication was 2004. The median sample size was 604 and ranged from 60 to 78,715 . Three studies used a case-control design and the remaining nine were cross-sectional.

In five studies, youth who reported using MA were compared to youth who did not use illicit drugs, hereafter referred to as "low-risk" youth. These low-risk youth were sampled from school populations. For the remaining seven studies, youth who reported using MA were compared to youth who abused illicit drugs other than MA, and/or youth who were sampled from juvenile detention centers, hereafter referred to as "high-risk" youth. Youth were recruited from a variety of locations, including schools, detention centers, juvenile homes, or treatment facilities. One study included youth up to the age of 24 and one study did not report the age of participants. The studies assessed a variety of risk factors, including demographic variables, mental health status, and risky behaviors.

\section{Methodological quality of included studies}

The median Downs and Black score was 15 of a possible score of 29 and ranged from 12 to 28 [Table 1] suggesting a risk of bias for those studies that received lower quality scores. Six of the twelve studies reported adjusted results, 


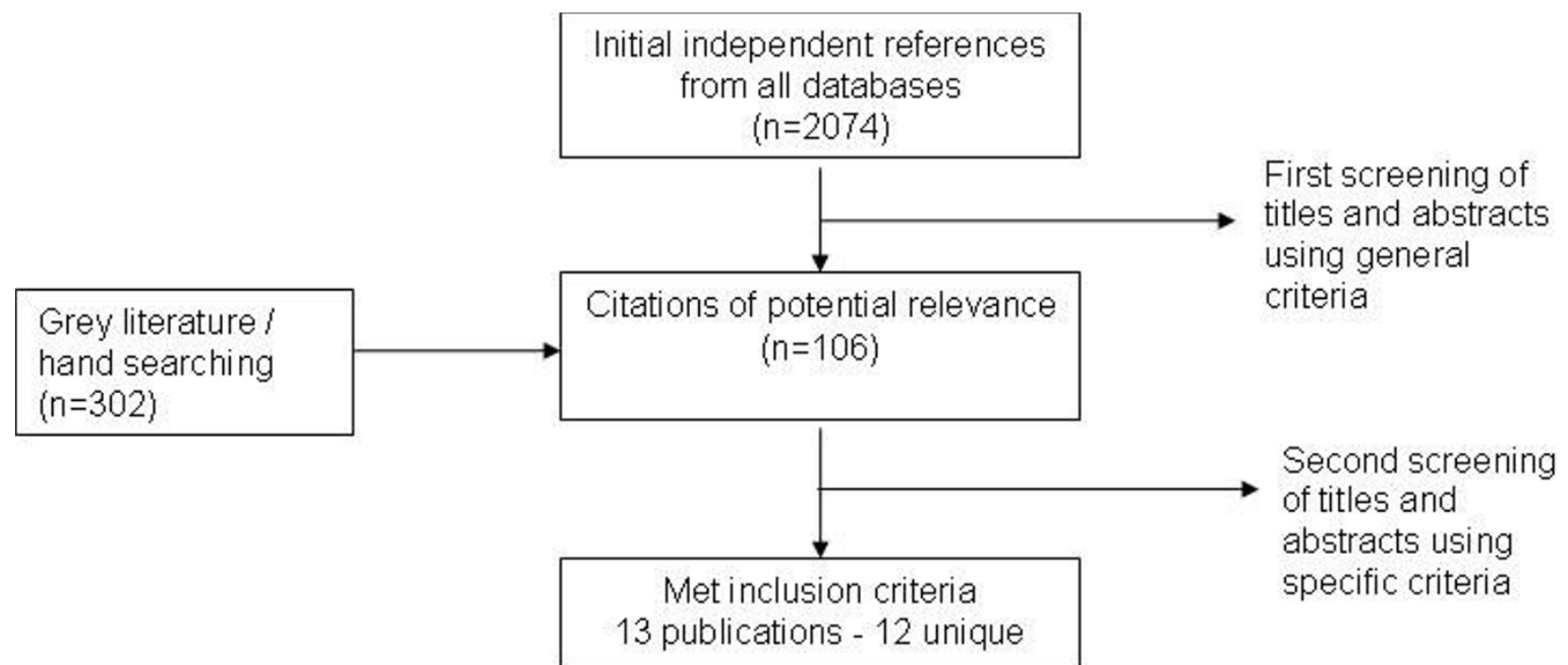

Figure I

Study retrieval and selection of studies investigating risk factors for MA use.

that is, the risk factor of interest was adjusted for other potentially confounding risk factors[23,26,28,31,32,34]. Six studies disclosed their funding source and the most common source was a government agency[23,26,29, $30,32]$.

\section{Quantitative results: comparing MA users to low-risk youth}

Five studies compared risk factors for MA among low-risk youth, as defined above (Table 2) [23,24,26,28,29]. There was considerable heterogeneity among the studies, which precluded the calculation of pooled estimates of effects in most cases. Pooled estimates are presented where appropriate.

Sex

Two cross-sectional studies examined sex as a risk factor and both independently indicated a significant association showing that males are more likely to use MA than females[26,29].

\section{Ethnicity}

One cross-sectional study using survey data examined ethnicity as a risk factor for MA[29]. The results showed that Caucasian youth were more likely to use MA than AfricanAmerican youth and Asian youth. However, Caucasian youth were significantly less likely to use MA than Hispanic and Native American youth.

\section{Years of education}

One case-control[23] and two cross-sectional studies[24,26] examined education as a risk factor for MA use and all three studies concluded that MA use was signifi- cantly associated with fewer years of education. Two studies reported the mean years of education among MA users and non-MA users. The pooled WMD indicated that nonMA users had more years of education than youth who used MA (WMD = 2.63; 95\% CI: 2.45 to 2.80)[24,25]. The third study categorized respondents' educational attainment of Grades 1-3 versus Grades 4 or more and also showed that non-MA users were 1.3 times more likely to have more education (95\% CI: 1.06 to 1.62$)$ [26].

\section{Sexual behavior}

Two cross-sectional studies independently reported a significant association between having ever previously engaged in sexual intercourse and using $\mathrm{MA}[8,36]$. One study found the following behaviors were significantly associated with MA use: engaging in unprotected sex, engaging in unplanned sex under the influence of alcohol, and engaging in sexual intercourse with an alcohol-intoxicated partner[24].

\section{Alcohol, cigarette and opiate use}

Two studies (one case-control[23] and one cross-sectional[26]) independently reported statistically significant associations between alcohol use, smoking, and heroin/opiate use.

\section{Psychiatric disorders}

Two studies of the same population examined the relationship between psychiatric disorders and MA use; however, the studies did not examine the same psychiatric conditions and their results could not be pooled[23,25]. The presence of the following conditions were found to be significantly associated with MA use: having any psychiat- 
Table I: Risk factors for MA: quality of included studies

\begin{tabular}{|c|c|c|c|c|}
\hline Study Year & Study Design & Downs and Black Score & Present Adjusted OR & Funding Source \\
\hline \multicolumn{5}{|c|}{ Low-risk youth as the comparison group } \\
\hline Lampinen 2006 & Cross-sectional & 15 & Yes & Other \\
\hline Oetting 2000 & Cross-sectional & 12 & No & Government \\
\hline Sattah 2002 & Cross-sectional & 15 & Yes & Government \\
\hline Yen $2006^{a}$ & Case-control & 15 & Yes & Government \\
\hline Yen $2004 b$ & Cross-sectional & 13 & No & NR \\
\hline \multicolumn{5}{|c|}{ High-risk youth as the comparison group } \\
\hline Kim 2002 & Cross-sectional & 16 & No & Government \\
\hline Miura 2006 & Case-control & 15 & Yes & NR \\
\hline Palmer 2005 & Case-control & 13 & No & NR \\
\hline Rawson 2005 & Cross-sectional & 14 & Yes & NR \\
\hline Shillington 2005 & Cross-sectional & 18 & Yes & Other \\
\hline Shillington 2003 & Cross-sectional & 17 & No & NR \\
\hline Uchida 1995 & Cross-sectional & 12 & No & NR \\
\hline
\end{tabular}

a Age and sex matched

b Sex matched

ric disorder, adjustment disorder, conduct disorder, and attention deficit and hyperactivity disorder (ADHD). Oppositional defiance disorder, anxiety disorder, major depressive disorder, dysthmic disorder, bipolar disorder, and eating disorder were not significantly associated with MA use among low-risk youth.

\section{Other risk factors}

Several other risk factors were associated with MA use among low-risk youth: being homosexual or bisexual[28], experiencing disruptive parenting[23], peers using or providing MA[23], and family history of drug use[23].

\section{Multivariate analyses}

Three studies conducted adjusted or multivariable logistic regression analyses (i.e., the risk factor of interest was adjusted for other potentially confounding factors). Lampinen et al. found that age and sexual preference were significant risk factors for MA use; sex was not found to be a risk factor in their analysis[28]. After adjusting for other psychiatric conditions and peer and family characteristics, Sattah et al. reported that the following risk factors were associated with MA use: recent alcohol or tobacco use, history of marijuana use, not having a family confidant, peer pressure, having a positive attitude towards MA use, and sexual experience[26]. The third study found that conduct disorder, a positive attitude toward MA use, poor understanding of MA use, disruptive parenting, low level of caregiver education, friends using or providing MA, and a more interactive interaction with peers were significant risk factors for MA[25]. Sex was not found to be statistically significant in this multivariable analysis.

\section{Quantitative results: comparing MA users to high-risk youth}

Seven studies examined risk factors for MA among highrisk youth (Table 3 ) [27,30-35]. Because of substantial heterogeneity among the studies, pooling of estimates was generally not appropriate.

Sex

Five studies (one case-control and four cross-sectional) independently reported that female sex was significantly associated with MA use[30,31,33-35]. 
Table 2: Comparing MA users to Low-Risk Youth

\begin{tabular}{|c|c|c|c|c|}
\hline Risk Factor & Study & Statistical Measure & Point Estimate $(95 \% \mathrm{Cl})$ & Conclusion \\
\hline \multirow[t]{2}{*}{$\operatorname{Sex}^{\mathrm{a}}$} & Oetting 2000 & OR & $0.72(0.70,0.75)$ & $\begin{array}{l}\text { Odds of using MA were higher for } \\
\text { males. }\end{array}$ \\
\hline & Sattah 2002 & OR & $0.34(0.27,0.43)$ & \\
\hline \multirow[t]{4}{*}{ Years of education } & Yen 2004 & MD & $2.70(2.36,3.04)$ & $\begin{array}{l}\text { Odds of using MA were higher for } \\
\text { those with less education. }\end{array}$ \\
\hline & Yen 2006 & MD & $2.60(2.40,2.80)$ & \\
\hline & Pooled b & WMD & $2.63(2.45,2.80)$ & \\
\hline & Sattah 2002 & OR & $1.31(1.06,1.62)$ & \\
\hline \multirow[t]{2}{*}{ Sexual behavior } & Sattah 2002 & OR & $2.79(2.25,3.46)$ & $\begin{array}{l}\text { Odds of using MA was higher for those } \\
\text { who had previously engaged in sexual } \\
\text { intercourse. }\end{array}$ \\
\hline & Yen 2004 & OR & $31.79(15.56,64.93)$ & \\
\hline \multirow[t]{2}{*}{ Alcohol use } & Sattah 2002 & OR & $8.02(4.53,14.18)$ & $\begin{array}{l}\text { Odds of using MA was higher for those } \\
\text { who drink alcohol. }\end{array}$ \\
\hline & Yen 2006 & OR & $51.31(12.27,214.68)$ & \\
\hline \multirow[t]{2}{*}{ Heroin/opiate use } & Sattah 2002 & OR & $30.66(9.38,100.17)$ & $\begin{array}{l}\text { Odds of using MA was higher for those } \\
\text { who had a history of heroin/opiate use. }\end{array}$ \\
\hline & Yen 2006 & OR & $22.53(1.24,409.59)$ & \\
\hline \multirow[t]{2}{*}{ Smoking } & Sattah 2002 & OR & $13.72(10.69,17.60)$ & $\begin{array}{l}\text { Odds of using MA were higher for } \\
\text { those who smoke. }\end{array}$ \\
\hline & Yen 2006 & OR & I54.85 (8I.95, 292.60) & \\
\hline Family history of drug use & Yen 2006 & OR & $8.65(3.88,19.25)$ & $\begin{array}{l}\text { Odds of using MA were higher for } \\
\text { youth with family history of drug use. }\end{array}$ \\
\hline Homosexual or bisexual & Lampinen 2006 & OR & $17.02(4.83,60.01)$ & $\begin{array}{l}\text { Odds of using MA were higher for } \\
\text { youth who were homosexual or } \\
\text { bisexual. }\end{array}$ \\
\hline Experiencing disruptive parenting & Yen 2006 & OR & $7.84(5.25$, II.7I) & $\begin{array}{l}\text { Odds of using MA were higher for } \\
\text { youth who experienced disruptive } \\
\text { parenting. }\end{array}$ \\
\hline Peers using or providing MA & Yen 2006 & OR & $40.94(24.64,68.03)$ & $\begin{array}{l}\text { Odds of using MA were higher for } \\
\text { youth with peers using or providing } \\
\text { MA. }\end{array}$ \\
\hline Engaging in unprotected sex & Yen 2004 & OR & I5.68 $(8.04,30.58)$ & $\begin{array}{l}\text { Odds of using MA were higher for } \\
\text { youth who engaged in unprotected } \\
\text { sex. }\end{array}$ \\
\hline $\begin{array}{l}\text { Engaging in unplanned sex under } \\
\text { the influence of alcohol }\end{array}$ & Yen 2004 & OR & $70.42(9.34,531.06)$ & $\begin{array}{l}\text { Odds of using MA were higher for } \\
\text { youth who engaged in unplanned sex } \\
\text { under the influence of alcohol. }\end{array}$ \\
\hline $\begin{array}{l}\text { Engaging in sex with an alcohol- } \\
\text { intoxicated partner }\end{array}$ & Yen 2004 & OR & $29.33(6.70,128.36)$ & $\begin{array}{l}\text { Odds of using MA were higher for } \\
\text { youth who engaged in sexual } \\
\text { intercourse with an alcohol- } \\
\text { intoxicated partner. }\end{array}$ \\
\hline Any psychiatric disorder & Yen 2006 & OR & $3.05(2.12,4.39)$ & $\begin{array}{l}\text { Odds of using MA were higher for } \\
\text { youth who had any psychiatric } \\
\text { disorder. }\end{array}$ \\
\hline Adjustment disorder & Yen 2006 & OR & $2.89(1.53,5.47)$ & $\begin{array}{l}\text { Odds of using MA were higher for } \\
\text { youth who had adjustment disorder. }\end{array}$ \\
\hline Conduct disorder & Yen 2006 & OR & $31.91(16.06,63.41)$ & $\begin{array}{l}\text { Odds of using MA were higher for } \\
\text { youth who had conduct disorder. }\end{array}$ \\
\hline $\begin{array}{l}\text { Attention-deficit hyperactivity } \\
\text { disorder }\end{array}$ & Yen 2006 & OR & $2.84(1.81,4.47)$ & $\begin{array}{l}\text { Odds of using MA were higher for } \\
\text { youth who had ADHD. }\end{array}$ \\
\hline
\end{tabular}

a Female $=1$, Male $=0$

b Combine Yen 2004 and Yen 2006, $\left.\right|^{2}=0 \%$

\section{Age}

One cross-sectional study categorized participants into two age groups: $13-14$ years and $15-18$ years[31]. The results show that age was not significantly associated with MA use.

\section{Ethnicity}

Three studies (one case-control and two cross-sectional) examined the association between ethnicity and MA use among high-risk youth[27,31,32]. Compared to AfricanAmerican and Asian youth, Caucasian youth were significantly more likely to use MA. There was no significant dif- 
Table 3: Comparing MA Users to High-Risk Youth

\begin{tabular}{|c|c|c|c|}
\hline Risk Factor & Study & OR $(95 \% \mathrm{Cl})$ & Conclusion \\
\hline \multirow[t]{5}{*}{$\operatorname{Sex}^{\mathrm{a}}$} & Uchida 1995 & $6.55(2.34,18.34)$ & Females were more likely to use MA than males. \\
\hline & Kim 2002 & $1.53(1.27,1.85)$ & \\
\hline & Shilungton 2003 & $4.00(3.49,4.58)$ & \\
\hline & Rawson 2005 & $9.53(5.40,16.79)$ & \\
\hline & Miura 2006 & $4.57(2.92,7.17)$ & \\
\hline$A g e^{b}$ & Rawson 2005 & $2.10(0.84,5.26)$ & Age was no significantly associated with MA use. \\
\hline Alcohol use & Rawson 2005 & $1.04(0.56,1.95)$ & $\begin{array}{l}\text { No association between a history of alcohol use and MA } \\
\text { use }\end{array}$ \\
\hline Family history of crime ${ }^{c}$ & Miura 2006 & $2.00(1.22,3.29)$ & $\begin{array}{l}\text { Odds of using MA was higher for youth with family history } \\
\text { of crime. }\end{array}$ \\
\hline Family history of drug use & Miura 2006 & $4.70(2.79,7.90)$ & $\begin{array}{l}\text { Odds of using MA was higher for youth with family history } \\
\text { of drug use. }\end{array}$ \\
\hline \multirow[t]{3}{*}{ Family history of alcohol abuse } & Uchida 1995 & $3.61(1.39,9.39)$ & $\begin{array}{l}\text { Odds of using MA was higher for youth with family history } \\
\text { of alcohol abuse. }\end{array}$ \\
\hline & Miura 2006 & $2.94(1.44,6.00)$ & \\
\hline & Pooledc & $3.16(1.78,5.61)$ & \\
\hline \multirow[t]{3}{*}{ Child abuse } & Uchida 1995 & $3.13(1.24,7.92)$ & $\begin{array}{l}\text { Odds of using MA was higher for youth who experienced } \\
\text { child abuse; the association was not statistically significant. }\end{array}$ \\
\hline & Miura 2006 & $1.49(0.73,3.07)$ & \\
\hline & Pooled ${ }^{d}$ & $2.04(0.99,4.17)$ & \\
\hline Receiving psychiatric treatment & Miura 2006 & $6.78(3.55,12.94)$ & $\begin{array}{l}\text { Odds of using MA was higher for youth who were receiving } \\
\text { psychiatric treatment. }\end{array}$ \\
\hline Greater than two admissions to juvenile home & Miura 2006 & $2.70(1.77,4.13)$ & $\begin{array}{l}\text { Odds of using MA was higher for youth with greater than } \\
\text { two admissions to juvenile home. }\end{array}$ \\
\hline History of violence & Miura 2006 & $0.35(0.20,0.62)$ & $\begin{array}{l}\text { Odds of using MA was lower for youth with history of } \\
\text { violence. }\end{array}$ \\
\hline Strict parental monitoring & Shillington 2005 & $0.25(0.11,0.57)$ & $\begin{array}{l}\text { Odds of using MA was lower for youth with strict parental } \\
\text { monitoring. }\end{array}$ \\
\hline
\end{tabular}

a Female $=1$, Male $=0$

b $13-14$ years vs. $15-18$ years

$c p^{2}=0 \%$

$d{ }^{2}=34.7 \%$

ference in MA use between Caucasian versus Hispanic, Asian, or Native American.

\section{Alcohol use}

One cross-sectional study found no association between a history of alcohol use and MA use[31].
Family history

One cross-sectional study found that a family history of crime or drug use was significantly associated with MA use [34]. The pooled analysis of two cross-sectional studies showed a significant association between family history of alcohol abuse and MA use[34,35]. 


\section{Child abuse}

The pooled analysis of one cross-sectional and one casecontrol study showed a two-fold association between children who experienced abuse and MA use; however, the result was not statistically significant $[34,35]$.

\section{Other risk factors}

The following factors were significantly associated with MA use: receiving psychiatric treatment, greater than two admissions to juvenile home, and history of violence[34]. However, strict parental monitoring was found to be protective for MA use among high-risk youth[32].

\section{Multivariable analyses}

Three studies conducted a multivariable logistic regression analysis. Shillington et al. found that strict parental monitoring, after controlling for age, was a statistically significant protective factor against MA use among highrisk youth[32]. After controlling for age and race, Rawson et al. found that female sex was significantly associated with MA use[31]. In the third study, female sex, age, more than two admissions to a juvenile home, non-violent history, psychiatric treatment, family history of drug misuse, and child abuse were significantly associated with MA use; a family history of crime was not significantly associated with MA use[34].

\section{Discussion and conclusion}

This systematic review presents the best-available evidence regarding risk factors for MA use among youth. An exhaustive search of over 40 electronic databases, grey literature, and hand searching identified 12 unique studies that met our inclusion criteria. The majority of the studies $(9 / 12)$ were cross-sectional in design and therefore it is not possible to determine whether the risk factors precede or follow MA use.

Because we believe that factors associated with MA use may differ among socially integrated (i.e., low-risk) and marginalized (i.e., high-risk) youth, we chose to analyze these studies separately. Compared to low-risk youth, there were some clear patterns of risk factors associated with MA use. A history of engaging in a variety of risky behaviors (e.g., sexual activity [planned, unplanned, or under the influence of alcohol], alcohol consumption, and opiate use) was significantly associated with MA use among low-risk youth. Engaging in high-risk behavior may be a gateway for MA use or vice versa. Homosexual or bisexual lifestyle is also a risk factor. This is not surprising, as MA is believed to heighten sexual pleasure and gay and bisexual men cite this as a reason for using MA[36]. A history of a psychiatric disorder and, in particular, adjustment disorder, conduct disorder, or ADHD, is a risk factor for MA use. This is consistent with previous research that shows psychiatric conditions to be risk factors for drug use in general[37].

Several risk factors were associated with MA use among high risk youth (i.e., those that used other illicit drugs or were in detention/juvenile centers). Unlike low-risk youth, females were significantly more likely to use MA. Youth who grew up in an unstable family environment (e.g., family history of crime, alcohol use, and drug use) were significantly more likely to use MA. While child abuse was not a significant risk factor, it approached statistical significance. High-risk youth who had received treatment for psychiatric conditions were more likely to use MA. One study found that strict parental monitoring was found to be protective against MA use among this group of youth.

\section{Limitations}

There were only 12 studies that met our inclusion criteria. These studies were fairly heterogeneous, which precluded pooling of results for most risk factors. Furthermore, many of the risk factors were assessed in only one study and the sample size was small. This is reflected in the wide confidence intervals and imprecise effect estimates. Most studies were either cross-sectional or retrospective making it impossible to assess a causal relationship between the risk factors and MA use. As with any systematic review, there is the possibility of publication and selection bias. However, we feel the risk for publication bias was minimized by our exhaustive search process. In addition to electronic databases, the reference lists of the included studies were searched, relevant conference proceedings and key journals were hand searched, and a thorough grey literature search was conducted.

\section{Implications for clinicians and front-line workers}

Youth who engage in risk-taking behaviors, live in an unstable home environment, have a psychiatric condition, and have peers that use or sell MA have a higher propensity for MA use. In order to identify youth at risk for MA use, health care workers and counsellors need to conduct a holistic assessment that includes psychiatric, lifestyle, and family history.

\section{Authors' contributions}

KR co-ordinated the project, prepared the manuscript, and assisted with assessing studies for inclusion, methodological quality assessment, data extraction, summarizing the qualitative results.

DD provided methodological expertise and provided feedback on the manuscript.

YL completed the statistical analysis and provided feedback on the manuscript. 
CF designed and executed the literature searches. She coordinated and assisted with all stages of the systematic review process, including manuscript preparation, related to the policy component.

KO assisted with assessing studies for inclusion, methodological quality assessment, data extraction, summarizing the qualitative results, and provided feedback on the manuscript.

TD assisted with designing and executing the literature searches and provided feedback on the manuscript. She also assisted with assessing studies for inclusion, methodological quality assessment, and data extraction.

TCW provided methodological and clinical expertise and provided feedback on the manuscript.

TPK provided methodological and clinical expertise and provided feedback on the manuscript.

\section{Additional material}

\section{Additional File 1}

Electronic Databases and Search Strategies. This file contains the literature databases and search strategies.

Click here for file

[http://www.biomedcentral.com/content/supplementary/1471-

2431-8-48-S1.doc]

\section{Additional File 2}

Table1. Risk factors for methamphetamine use: description of the population. This file contains a table.

Click here for file

[http://www.biomedcentral.com/content/supplementary/14712431-8-48-S2.doc]

\section{Additional File 3}

Table2. Risk factors for methamphetamine use: description of the risk factors. The file contains a table.

Click here for file

[http://www.biomedcentral.com/content/supplementary/14712431-8-48-S3.doc]

\section{Acknowledgements}

This study was funded by the Alberta Centre for Child, Family, and Community Research. We are grateful to Yvonne Allan (Rural Alberta/Parent Representative), Kathy Collins (Alberta Solicitor General), David Cook (Pharmacology, University of Alberta), Pat Knoll (Law, University of Calgary), Marilyn Mitchell (Alberta Alcohol and Drug Addition Centre), Harold Trupish (Royal Canadian Mounted Police), and Wadieh Yacoub (Health Canada/First Nations) for their input. Carlynne Greidanus assisted with screening, quality assessment, and data extraction. We thank Liza Bialy and Karalee Ratzlaff for their assistance in article retrieval.

\section{References}

I. Albertson TE, Derlet RW, Van Hoozen BE: Methamphetamine and the expanding complications of amphetamines. West J Med 1999, I 70(4):214-9.

2. National Institute on Drug Abuse: NIDA Research Report Series: Methamphetamine abuse and addiction. Rockville, MD: U.S. Dept. of Health and Human Services, National Institutes of Health, National Institute on Drug Abuse; 2002. Research Report Series

3. Ministerial Action Group on Drugs: Methamphetamine Action Plan. Wellington, NZ: National Drug Policy; 2003.

4. Saul D: Western Canadian Summit on methamphetamine: bringing together practitioners, policy makers and researchers: consensus panel report. Vancouver, BC: Vancouver Coastal Health; 2005: I-48.

5. Klasser GD, Epstein J: Methamphetamine and its impact on dental care. J Can Dent Assoc 2005, 7 I ( I 0):759-62.

6. Lake CR, Quirk RS: CNS stimulants and the look-alike drugs. Psychiatr Clin North Am 1984, 7(4):689-70I.

7. Sulzer D, Sonders MS, Poulsen NW, Galli A: Mechanisms of neurotransmitter release by amphetamines: a review. Prog Neurobiol 2005, 75(6):406-33.

8. Marcelle G, ed: Methamphetamines: a guide for parents and other caregivers. Rockville, MD: U.S. Department of Health and Human Services, Substance Abuse and Mental Health Administration, National Clearinghouse for Alcohol and Drug Information; 1999.

9. Wray JN: Psychophysiological aspects of methamphetamine abuse. J Addict Nurs 2000, I 2:143-7.

10. Slavin S: Crystal methamphetamine use among gay men in Sydney. Contemporary Drug Problems 2004, 32:425-65.

II. Anglin MD, Burke C, Perrochet B, Stamper E, Dawud-Noursi S: History of the methamphetamine problem. I Psychoactive Drugs 2000, 2(2): | 37-4|.

12. Volkow ND, Chang L, Wang G], et al:: Association of dopamine transporter reduction with psychomotor impairment in methamphetamine abusers. Am J Psychiatry 2001, I 58(3):377-82.

13. Volkow ND, Chang L, Wang GJ, et al.: Loss of dopamine transporters in methamphetamine abusers recovers with protracted abstinence. J Neurosci 200I, 2 I:94I4-8.

14. Royal Canadian Mounted Police: K Division Methamphetamine Strategy [Web Page]. 2005 [http://www.rcmp-grc.gc.ca/ab/ prog serv/meth e.htm].

15. Parks L, Jack M, for the Alberta Centre for Child Family \& Community Research: Methamphetamines in Alberta: a focus on children, youth, and families [Web Page]. 2005 [http:// www.research4children.org/public/data/documents/

MethamphetamineReport2006FINALpdf.pdf].

16. Office of Applied Studies: Methamphetamine use, abuse, and dependence:2002, 2003, and 2004. National survey on drug use and health: The NSDUH Report. Rockwell, MD: Substance Abuse and Mental Health Services Administration; 2005.

17. Patton D, Brown D, Brozeit B, Dhaliwal J: Substance abuse among Manitoba high school students. Winnipeg, MB: Addictions Foundation of Manitoba; 2001 .

18. Centre for Addiction and Mental Health: Methamphetamine use down among Ontario students, 1999-2005. CAMH Population Studies EBulletin 2006, 7(2): I-2.

19. Downs $\mathrm{SH}$, Black $\mathrm{N}$ : The feasibility of creating a checklist for the assessment of the methodological quality both of randomised and non-randomised studies of health care interventions. J Epidemiol Community Health I998, 52(6):377-84.

20. DerSimonian R, Laird N: Meta-analysis in clinical trials. Control Clin Trials 1986, 7(3): |77-88.

21. Alderson P, Green S, Higgins JPT, eds: Cochrane Reviewers' Handbook 4.2.2. 2003.

22. Higgins JPT, Thompson SG, Deeks JJ, Altman DG: Measuring inconsistency in meta-analysis. BMJ 2003, 327:557-60.

23. Yen CF, Yang YH, Chong MY: Correlates of methamphetamine use for Taiwanese adolescents. Psychiatry Clin Neurosci 2006, 60(2): I60-7.

24. Yen CF: Relationship between methamphetamine use and risky sexual behavior in adolescents. Kaohsiung J Med Sci 2004, 20(4): I60-5.

25. Yen CF, Chong MY: Comorbid psychiatric disorders, sex, and methamphetamine use in adolescents: a case-control study. Compr Psychiatry 2006, 47(3):2I 5-20. 
26. Sattah MV, Supawitkul S, Dondero TJ, et al.: Prevalence of and risk factors for methamphetamine use in Northern Thai youth: results of an audio-computer-assisted self-interviewing survey with urine testing. Addiction 2002, 97(7):80I-8.

27. Palmer GA, Daiss DD: Personality characteristics of adolescents with hallucinogen, methamphetamine, and cannabis dependence: a comparative study. I Child Adolesc Subst Abuse 2005, I 5(I):37-49.

28. Lampinen T, McGhee D, Martin I: Use of crystal methamphetamine and other club drugs among high school students in Vancouver and Victoria. BCMJ 2006, 48(I):22-7.

29. Oetting ER, Deffenbacher JL, Taylor MJ, Luther N, Beauvais F, Edwards RW: Methamphetamine use by high school students: recent trends, gender and ethnicity differences, and use of other drugs. J Child Adolesc Subst Abuse 2000, I 0(I):33-50.

30. Kim JY, Fendrich M: Gender differences in juvenile arrestees' drug use, self-reported dependence, and perceived need for treatment. Psychiatr Serv 2002, 53(I):70-5.

31. Rawson RA, Gonzales R, Obert JL, McCann MJ, Brethen P: Methamphetamine use among treatment-seeking adolescents in Southern California: participant characteristics and treatment response. J Subst Abuse Treat 2005, 29(2):67-74.

32. Shillington AM, Lehman S, Clapp J, Hovell MF, Sipan C, Blumberg El: Parental monitoring: can it continue to be protective among high-risk adolescents? J Child Adolesc Subst Abuse 2005, I 5( I): I - I 5.

33. Shillington AM, Clapp JD: Adolescents in public substance abuse treatment programs: the impacts of sex and race on referrals and outcomes. I Child Adolesc Subst Abuse 2003, I 2(4):69-9I.

34. Miura H, Fujiki M, Shibata A, Ishikawa K: Prevalence and profile of methamphetamine users in adolescents at a juvenile classification home. Psychiatry Clin Neurosci 2006, 60(3):352-7.

35. Uchida C: Drug abuse and psychosocial background among juvenile delinquents: Correlation between self-destructive behaviors and traumatic experiences. International Medical Journal I995, 2(I):34-7.

36. Green Al, Halkitis PN: Crystal methamphetamine and sexual sociality in an urban gay subculture: an elective affinity. Cult Health Sex 2006, 8:317-33.

37. American Psychiatric Association: Division of Research and Division of Government Relations. Alcohol, drug abuse and mental disorders: reducing the economic and human costs [Web Page] [http:www.healthyminds.org/multimedia/alcoholdrugabusebro chure.pdf\#search=\%22psychiatric\%20disorder\%20as\%20risk\%20fa\%2 0for\%20methamphetamine\%20abuse\%22.]. 10 August 2006

\section{Pre-publication history}

The pre-publication history for this paper can be accessed here:

http://www.biomedcentral.com/1471-2431/8/48/prepub

\section{Publish with Bio Med Central and every scientist can read your work free of charge}

"BioMed Central will be the most significant development for disseminating the results of biomedical research in our lifetime. "

Sir Paul Nurse, Cancer Research UK

Your research papers will be:

- available free of charge to the entire biomedical community

- peer reviewed and published immediately upon acceptance

- cited in PubMed and archived on PubMed Central

- yours - you keep the copyright 